\title{
ODONTOMETRIC ANALYSIS USING CBCT FOR SEXUAL DIMORPHISM IN EGYPTIAN-FAYOUM POPULATION IN CASE OF NORMAL OCCLUSION
}

\author{
Engy Ali Abdelhaleem Salam*, Ayman Raouf Khalifa** and Dina Mohamed Hassouna***
}

\begin{abstract}
Background. Cone beam computed tomography (CBCT) can provide precise assistance in odontometric measurements and to investigate the existence of sexual dimorphism in population. Aim of this study was to evaluate odontometric linear measurements obtained from CBCT software including mesiodistal, tooth length dimensions and enamel thickness of the mandibular canine and mandibular first molar and arch measurements for sexual dimorphism in Egyptian population sample.

Material and Methods: The study was carried out on 100 subjects who visited the department of oral and maxillofacial radiology, Fayoum University for dental treatments. The study sample were grouped into two groups, group A (50 males) and group B (50 females) aged between 18-25 years old. CBCT examination was performed for all patients. The teeth which were selected for linear measurements using CBCT in the present study were 100 mandibular permanent canines (Lower 3) and 100 mandibular permanent 1st molar teeth (Lower 6), for each group respectively. The linear measurements were taken on crown width and height, Enamel thickness, arch depth and width.
\end{abstract}

Results: There was a highly significant difference between Male and Female for odontometric measurements of mandibular right and left canines and 1st molars including (CWL3, CLL3, CWL6 at contact level, CWL6 at CEJ level and CLL6) while enamel thickness measurements showed nonsignificant differences between males and females including (ETL3 at cusp tip, ETML6, ETDL6 and ETL6 at mesio-lingual cusp tip). Arch measurements including (ICW, IMW through fossa and IMW through contact) showed high significant differences between males and females. ADD measurements revealed non-significant differences between both sexes, whereas the ADM values in females were larger than males with high significant differences.

Conclusion: Odontometric parameters including mandibular canine, mandibular first molar crown width and length, inter-canine width and inter-molar width measurements based on CBCT imaging show highly significant gender difference. Thus, the parameters can be simple and reliable sexual dimorphism for medicolegal purpose and also it should be considered as part of the clinical diagnosis of orthodontic treatment and estimate of orthodontic clinical need in Egyptian population.

KEYWORDS: CBCT, sexual dimorphism, odontometric measurements, arch measurements, enamel thickness.

* Oral Radiology Department, Faculty of Dentistry, Fayoum University

** Department of Pedodontics and Orthodontics, October 6 University, Faculty of Dentistry, Cairo, Egypt

*** Lecturer of Oral Biology- Faculty of Dentistry- Fayoum University 


\section{INTRODUCTION}

Dental anatomical landmarks not only have physiological and clinical significance but also have a forensic significance. ${ }^{[1]}$ Since teeth are the hardest and chemically the most stable tissue in the body. As well as teeth have high mineral content especially in enamel and dentin tissues which constitute about 96\% and $70 \%$ mineralized components respectively. [1, 2] The biological components of tooth enamel have the ability to withstand drastic atmospheric conditions, prolonged immersion, desiccation, as well as excessive trauma. ${ }^{[3]}$ Due to such biological properties of the tooth, the tooth becomes highly resistant to bacterial disintegration. In addition, the tooth shows advantage to be more resistant to degradation than bones. Moreover, the tooth turns out to be more resistant to fracture and fire. ${ }^{[4-6]}$ Such characteristics make the tooth plays an important role in forensic researches and investigations. ${ }^{[7-9]}$

Lack of evidence to determine the identity of an individual in pathetic situations, such as mass murders, airplane crash, train and road accidents, fires, natural disasters like tsunamis, earthquakes and floods, is one of the most common problems in forensic investigations. ${ }^{[6,10]} \mathrm{Sex} / \mathrm{Gender}$ and age have been postulated by many authors to be the initial step in determining the identity of the skeletal remains in forensic investigations. ${ }^{[6,11,12]}$

Sex determination is usually identified from bone by osteometry. ${ }^{[7]}$ or from various human tissues by DNA analysis or from tooth through odontometric parameters. ${ }^{[6,13]}$ The DNA analysis can give an accurate result, but in many cases, it cannot be used as it is expensive, not readily available, involves difficult DNA extraction technique especially in fragmented parts of dead bodies after fires and explosions. ${ }^{[14,15]}$ Osteometry can give accurate results too, but bone shows a little resistance to fragmentation over tooth. ${ }^{[4,7]}$ Moreover, the badly mutilated bodies with fragmentary remnants of a skeletal tissues create a major problem in determining individual identity and in many instances the fragmented skeletal bodies may not be identifiable at all. ${ }^{[14,15]}$ Thus, odontometric measurements of the tooth plays an important role in determining the initial steps of the individual identity through sex and age. ${ }^{[11,16]}$

Sexual dimorphism represents a group of morphologic characteristics in form of shape or size that differentiate a male from a female. [3] Odontometric parameters of various species are known to exhibit sexual dimorphism. ${ }^{[17]}$ In present human population, males show larger tooth dimensions than females ${ }^{[18-21]}$

Orthodontic treatments always aimed to accomplish good occlusion with proper inter-digitation and good vertical and horizontal relationship. There must be balance between mesiodistal tooth sizes of the maxillary and mandibular arches. The different in crown dimension, arch perimeter, arch length and width in relation to sexual dimorphism may clinically affect the overbite and overjet. ${ }^{[22]}$ So, in order to reduce the expected malocclusion, there is a need to estimate and study the gender variation in tooth size and arch size discrepancy. Abuelazayem et al., 2014, stated that there was difference in severity of deep bite between male and female. greater percentage of males had moderate to severe deep bite. ${ }^{[23]}$

Of all the teeth in the human dentition, canines are the least frequently extracted teeth because of the relatively decreased incidence of caries and periodontal disease. ${ }^{[24,25]}$ Bansal et al 2008 considered mandibular canines as the key teeth for personal identification. Whereas, molars are the first permanent teeth to erupt in the oral cavity; and hence, they are readily available for use in sex assessment at an early age when compared with other permanent teeth. It scores an advantage over canines, which have greater tendency of being impacted and thus being unavailable for odontometric analysis. ${ }^{[6,26,27]}$

Recently, Imaging modalities with three-dimensional (3D) technologies like multislice CT, 
Cone-beam computerized tomography (CBCT) and Magnetic Resonance Imaging (MRI), allow effective imaging of three-dimensional structures and are systematically utilized for anthropometric assessment instead of the traditional direct caliper-based measurement on a model cast. ${ }^{[28,29]}$ They have been proved to be very valuable in mass fatality incidents. Moreover, dental radiography is broadly used in conjunction with the odontological examination to assist in postmortem identifications. ${ }^{[30]}$

CBCT was developed providing another threedimensional alternative to conventional medical CT with several advantages. The built-in error in medical CT scanners due to the accumulated gaps between slices is avoided in CBCT since volumes of data are captured with a single 360-degree rotation about the patient head. CBCT has proven to capture structures with high contrast and excellent volumetric image acquisition. In addition, CBCT exposes the patient to less radiation dose than medical CT. ${ }^{[31-33]}$

Moreover, CBCT can visualize and provide detailed information about teeth and surrounding anatomical structures, these advantages of CBCT make it a reliable tool for sex determination in forensic medicine. ${ }^{[12,34]}$

The objective of this study was to evaluate odontometric linear measurements obtained from CBCT software including mesiodistal, tooth length dimensions and enamel thickness of the mandibular canine and mandibular first molar and arch measurements for evaluation of the level of accuracy with which they can be used for sexual dimorphism in Egyptian population sample.

\section{MATERIALS AND METHODES}

The present study was carried on 100 subjects who visited the department of oral and maxillofacial radiology, Fayoum University for purposes rather than the study. The study sample were grouped into two groups, group A (50 males) and group B (50 females) aged between 18-25 years old.
Ethical approval was granted by the Ethics Committee of the faculty of Dentistry, October 6 University (RECO6U/7-2020), and informed consent was obtained from all subjects.

\section{In the current study the patients were selected according to the following criteria}

1. They belong to Fayoum city.

2. The patients have normal occlusion where, the mesio-buccal cusp tip of upper $1^{\text {st }}$ permanent molar (upper 6) is situated in mesio-buccal developmental groove of lower $1^{\text {st }}$ permanent molar (lower 6). In addition, the upper permanent canine (upper 3 ) is situated between lower canine and $1^{\text {st }}$ premolar

3. Teeth which were included in the present study were fully erupted teeth, periodontally healthy, non-carious teeth.

4. Teeth which were excluded in the present study were those subjected to physiological or pathological wearing (attrition, abrasion, erosion), malaligned teeth (crowding, rotation or malocclusion, spacing), partially erupted teeth, any history of restoration, orthodontic treatment or trauma.

The teeth which were selected for linear measurements using CBCT in the present study were 100 mandibular permanent canines (Lower 3 ) and 100 mandibular permanent 1 st molar teeth (Lower 6), for each group respectively.

CBCT examination was performed for all patients to undergo procedures or evaluations as removal of impacted lower or upper third molar or evaluation of any pathosis in both jaws that, not affecting our criteria of subject selection.

The Cone Beam Computer Tomography (CBCT) Device used in the present study is Planmeca, Promax 3D Max, Finland, with the following acquisition parameters: All scans were output with 512 X 512 pixels per slice and 8 bits per pixel. Resultant voxels 
were isotropic having identical length, width and depth of $0.16 \mathrm{~mm}$. The acquisition time for each slice was 12 seconds and the reconstruction time was 60 seconds at an angular increment of 0 degrees.

The linear measurements were taken on both right and left Lower permanent canines (R \& L L3) and mandibular $1^{\text {st }}$ permanent molar (R \& L L6)

1. Crown width or mesiodistal dimension of the tooth of right and left lower canines were measured on the coronal CBCT cut at points connecting mesial and distal contact areas CWL3.

2. Crown width or mesiodistal dimension of the tooth of right and left lower $1^{\text {st }}$ molar were measured on the sagittal CBCT cut at points connecting mesial and distal contact areas CWL6. ${ }^{[35]}$ (Fig. 1)

3. Crown length of right and left lower canines were measured on sagittal CBCT cut from level of cemento-enamel junction to cusp tip, after adjustment of the coronal orientation line along the long axis of the tooth (CLL3). (Fig. 2)

4. Crown length of right and left lower $1^{\text {st }}$ molar were measured on coronal CBCT cut from level of CEJ to central fossa after adjustment of sagittal orientation line along the long axis of the tooth (CLL6). (Fig. 3)

5. Enamel thickness of right and left lower canines from level of dentino-enamel junction (DEJ) to the maximum point on the cusp, the measurements were taken on the sagittal CBCT cut after adjustment of the coronal orientation line along the long axis of the tooth (ETL3) (Fig.2)

6. Enamel thickness of right and left lower $1^{\text {st }}$ molar at level of contact areas from DEJ, the measurement was taken on the sagittal CBCT cut after adjustment of the coronal orientation line along the long axis of the tooth and the axial orientation line along the mesial and distal contact points (ETML6, ETDL6). ${ }^{[36]}$ (Fig. 1)

7. Enamel thickness of right and left lower $1^{\text {st }}$ molar from DEJ to highest point on mesiolingual cusp measured on sagittal cut (ETL6) (Fig. 4)

\section{Arch measurements include}

1. Arch depth1 (ADM) which is a vertical line starting from the contact point of central incisors and end upon intersecting a horizontal line from mesial aspect of lower 6 from right side to left side.

2. Arch depth2 (ADD) which is a vertical line starting from the contact point of central incisors and end upon intersecting a horizontal line from distal aspect of lower 6 from right side to left side.

3. Inter canine width (ICW) from a mid-way point at the level of contact areas of lower 3 from right side to left side.

4. Inter molar width (IMW) from a mid-way point at the level of contact areas of lower 6 from right side to left side.

ADM, ADD, ICW and IMW measurements were done on the axial CBCT image. (Fig. 5)

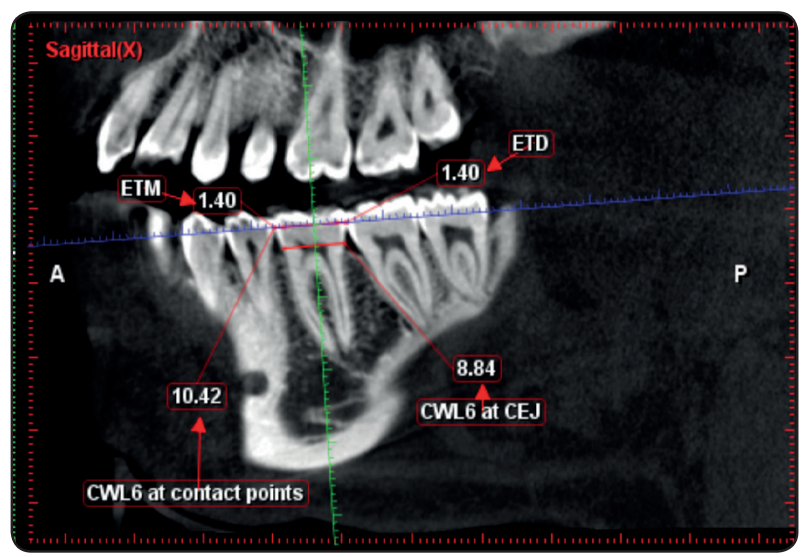

Fig. (1): CBCT sagittal cut showing lower left 1st molar odontometric measurements including, crown width at contact, crown width at CEJ, enamel thickness mesial (ETM) and enamel thickness distal (ETD). 


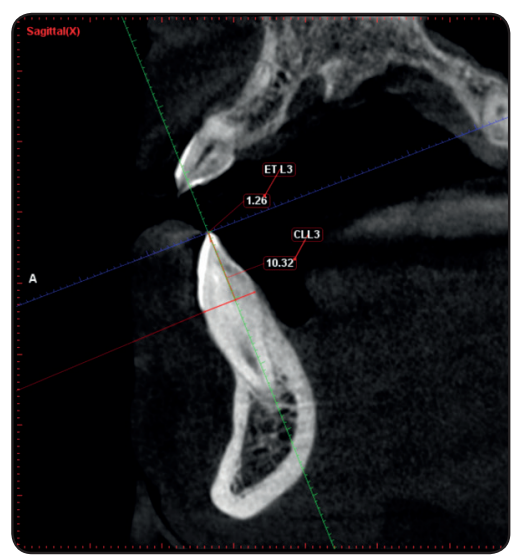

Fig. (2): CBCT sagittal cut showing lower left canine odontometric measurements including enamel thickness and crown length.

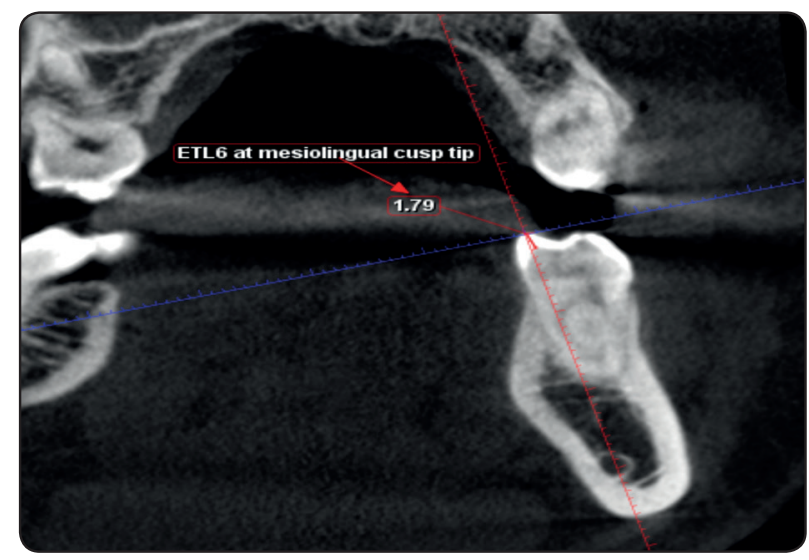

Fig. (4): CBCT coronal cut showing enamel thickness of lower left 1 st molar at mesiolingual cusp.

\section{Statistical analysis of survey methods:}

Data were unloaded by known Statistical Package for Social Sciences Statistical Program was the statistical analysis using the computer through a statistical package software SPSS V. 25 and through it, we used the following tests:

1. Descriptive statistics of the data through the tabulating data in the form of (frequencies and proportion).

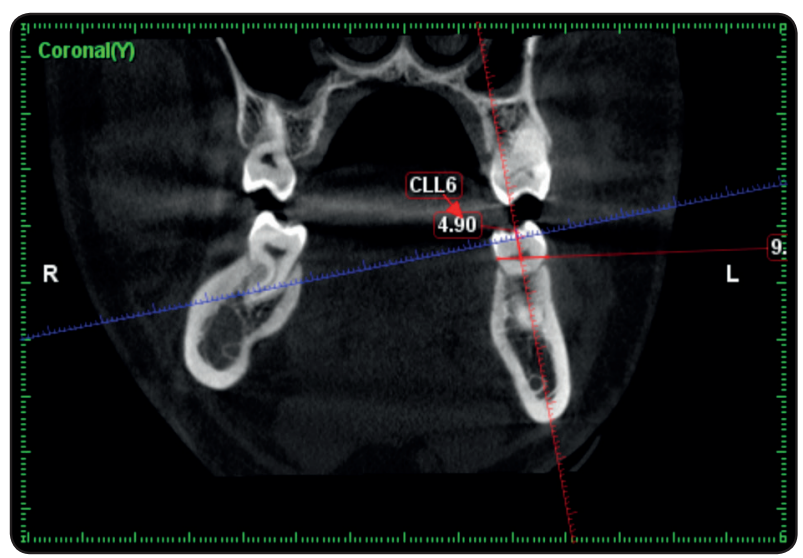

Fig. (3): CBCT coronal cut showing crown length of lower left 1st molar from a line drown through buccal and lingual CEJ to fossa

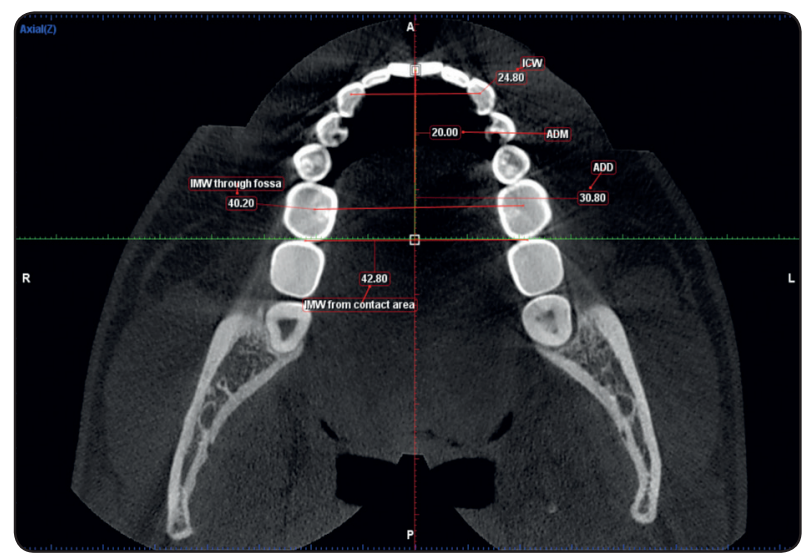

Fig. (5): CBCT axial cut showing arch measurements including inter-canine width (ICW), arch depth from mesial contact points of right and left lower first molar (ADM), arch depth (ADD), inter-molar width (IMW) through fossa, inter-molar width through contact points.

2. Discriminant analysis

3. T- Test to illustrate the differences between the study sample according to Gender.

\section{RESULTS}

The total number of (Males) was 50 with percent (50.0\%), number of (Females) was 50 with percent $(50.0 \%)$ also. 
TABLE (1) T- Test to illustrate the differences between the study sample according to Gender Lower canines

\begin{tabular}{|c|c|c|c|c|c|c|c|c|c|c|c|c|}
\hline \multirow{4}{*}{$\begin{array}{c}\text { Variable } \\
\text { CWL3 }\end{array}$} & \multicolumn{6}{|c|}{ Right } & \multicolumn{6}{|c|}{ Left } \\
\hline & \multirow{2}{*}{\multicolumn{2}{|c|}{$\begin{array}{l}\text { Male }(n=50) \\
\text { Mean } \pm \text { SD }\end{array}$}} & \multirow{2}{*}{\multicolumn{2}{|c|}{$\begin{array}{c}\text { Female }(n=50) \\
\text { Mean } \pm \text { SD }\end{array}$}} & \multirow{3}{*}{$\begin{array}{c}\mathbf{T} \\
13.168\end{array}$} & \multirow{3}{*}{$\begin{array}{c}\text { P-value } \\
0.001 \mathrm{HS}\end{array}$} & \multirow{2}{*}{\multicolumn{2}{|c|}{$\begin{array}{l}\text { Male }(n=50) \\
\text { Mean } \pm \text { SD }\end{array}$}} & \multirow{2}{*}{\multicolumn{2}{|c|}{$\begin{array}{c}\text { Female }(n=50) \\
\text { Mean } \pm \text { SD }\end{array}$}} & \multirow{3}{*}{$\begin{array}{c}\mathbf{T} \\
9.845\end{array}$} & \multirow{3}{*}{$\begin{array}{c}\text { P-value } \\
0.001 \mathrm{HS}\end{array}$} \\
\hline & & & & & & & & & & & & \\
\hline & 7.0168 & 0.29 & 6.3082 & 0.25 & & & 6.9784 & 0.41 & 6.2958 & 0.28 & & \\
\hline CLL3 & 9.9164 & 0.58 & 9.3612 & 0.97 & 3.476 & $0.001 \mathrm{HS}$ & 10.1974 & 0.47 & 9.2836 & 0.86 & 6.60 & $0.001 \mathrm{HS}$ \\
\hline ETL3 & 1.5460 & 0.42 & 1.4192 & 0.19 & 1.946 & $0.06 \mathrm{NS}$ & 1.6968 & 0.38 & 1.5904 & 0.15 & 1.83 & $0.07 \mathrm{NS}$ \\
\hline
\end{tabular}

HS significant at (0.01)

Table (1) showed the differences between the study sample according to Gender Lower canines (Right) as following:

- There was a highly significant difference at p-value (0.01) between (Male) and (Female) for (CWL3) where (T) value was (13.168) with p-value (0.001), the mean of (Male) (7.0163) and the mean of (Female) (6.3082).

- There was a highly significant difference at p-value (0.01) between (Male) and (Female) for (CLL3) where (T) value was (3.476) with p-value (0.001), the mean of (Male) (9.9164) and the mean of (Female) (9.3612).

- There was non-significant difference at p-value (0.05) between (Male) and (Female) for (ETL3) where $(\mathrm{T})$ value was (1.946) with p-value (0.06), the mean of (Male) (1.546) and the mean of (Female) (1.4192).

Table (1) showed the differences between the study sample according to Gender Lower canines (Left) as following:

- There was a highly significant difference at pvalue (0.01) between (Male) and (Female) for (CWL3) where $(\mathrm{T})$ value was $(9.845)$ with $\mathrm{p}$ value (0.001), the mean of (Male) (6.9784) and the mean of (Female) (6.2958).
NS non-significant at $(0.05)$

- There was a highly significant difference at p-value (0.01) between (Male) and (Female) for (CLL3) where (T) value was (6.600) with p-value (0.001), the mean of (Male) (10.1974) and the mean of (Female) (9.2836).

- There was non-significant difference at p-value (0.05) between (Male) and (Female) for (ETL3) where $(\mathrm{T})$ value was (1.830) with p-value (0.07), the mean of (Male) (1.6968) and the mean of (Female) (1.5904).

Table (2) showed the differences between the study sample according to Gender of Lower permanent $1^{\text {st }}$ molar (lower 6) (Right) as the following:

- There was a highly significant difference at p-value (0.01) between (Male) and (Female) for (CWL6) where (T) value was (5.652) with p-value (0.001), the mean of (Male) (11.4024) and the mean of (Female) (10.666).

- There was a highly significant difference at p-value (0.01) between (Male) and (Female) for (CWL6 at CEJ) where (T) value was (3.077) with p-value (0.003), the mean of (Male) (9.5068) and the mean of (Female) (9.052).

- There was a highly significant difference at p-value (0.01) between (Male) and (Female) for (CLL6) where (T) value was (10.439) with p-value (0.001), the mean of (Male) (5.322) and the mean of (Female) (4.6012). 
TABLE (2) T- Test to illustrate the differences between the study sample according to Gender of Lower permanent $1^{\text {st }}$ molar (lower 6 )

\begin{tabular}{|c|c|c|c|c|c|c|c|c|c|c|c|c|}
\hline \multirow{4}{*}{$\begin{array}{c}\text { Variable } \\
\text { CWL6 (width) }\end{array}$} & \multicolumn{6}{|c|}{ Right } & \multicolumn{6}{|c|}{ Left } \\
\hline & \multirow{2}{*}{\multicolumn{2}{|c|}{$\begin{array}{l}\text { Male }(n=50) \\
\text { Mean } \pm \text { SD }\end{array}$}} & \multirow{2}{*}{\multicolumn{2}{|c|}{$\begin{array}{c}\text { Female }(n=50) \\
\text { Mean } \pm \text { SD }\end{array}$}} & \multirow{3}{*}{$\begin{array}{c}\mathbf{T} \\
5.652\end{array}$} & \multirow{3}{*}{\begin{tabular}{|l|} 
P-value \\
$0.001 \mathrm{HS}$
\end{tabular}} & \multirow{2}{*}{\multicolumn{2}{|c|}{$\begin{array}{l}\text { Male }(n=50) \\
\text { Mean } \pm \text { SD }\end{array}$}} & \multirow{2}{*}{\multicolumn{2}{|c|}{$\begin{array}{c}\text { Female }(n=50) \\
\text { Mean } \pm \text { SD }\end{array}$}} & \multirow{3}{*}{$\begin{array}{c}\mathbf{T} \\
4.626\end{array}$} & \multirow{3}{*}{$\begin{array}{l}\text { P-value } \\
0.001 \mathrm{HS}\end{array}$} \\
\hline & & & & & & & & & & & & \\
\hline & 11.4024 & 0.67 & 10.666 & 0.63 & & & 11.336 & 0.74 & 10.7492 & 0.51 & & \\
\hline CWL6 at CEJ & 9.5068 & 0.81 & 9.052 & 0.66 & 3.077 & $0.003 \mathrm{HS}$ & 9.4874 & 0.79 & 8.950 & 0.52 & 4.017 & $0.001 \mathrm{HS}$ \\
\hline CLL6 (length) & 5.322 & 0.44 & 4.6012 & 0.22 & 10.439 & $0.001 \mathrm{HS}$ & 5.273 & 0.44 & 4.511 & 0.22 & 10.946 & $0.001 \mathrm{HS}$ \\
\hline $\begin{array}{l}\text { ETML6 (enamel } \\
\text { mesial right) }\end{array}$ & 1.2688 & 0.15 & 1.2584 & 0.09 & 0.4434 & $0.7 \mathrm{NS}$ & 1.3388 & 0.09 & 1.3054 & 0.1 & 1.836 & $0.07 \mathrm{NS}$ \\
\hline $\begin{array}{c}\text { ETDL6 (enamel } \\
\text { Distal right) }\end{array}$ & 1.4062 & 0.11 & 1.3508 & 0.18 & 1.857 & $0.07 \mathrm{NS}$ & 1.4490 & 0.08 & 1.4002 & 0.17 & 1.832 & $0.07 \mathrm{NS}$ \\
\hline $\begin{array}{c}\text { ETL6 } \\
\text { (AT CUSP TIP) }\end{array}$ & 1.7878 & 0.12 & 1.722 & 0.22 & 1.831 & $0.07 \mathrm{NS}$ & 1.7750 & 0.24 & 1.7024 & 0.16 & 1.766 & $0.08 \mathrm{NS}$ \\
\hline
\end{tabular}

HS significant at (0.01)

- There was non-significant difference at p-value (0.05) between (Male) and (Female) for (ETML6) where (T) value was (0.434) with p-value (0.7), the mean of (Male) (1.2688) and the mean of (Female) (1.2584).

- There was non-significant difference at $\mathrm{p}$-value (0.05) between (Male) and (Female) for (ETDL6) where (T) value was (1.857) with p-value (0.07), the mean of (Male) (1.4062) and the mean of (Female) (1.3508).

- There was non-significant difference at p-value (0.05) between (Male) and (Female) for (ETL6) where $(\mathrm{T})$ value was (1.831) with p-value (0.07), the mean of (Male) (1.7878) and the mean of (Female) (1.722).

Table (2) showed the differences between the study sample according to Gender of Lower permanent $1^{\text {st }}$ molar (lower 6) (Left) as the following:

- There was a highly significant difference at p-value (0.01) between (Male) and (Female)
NS non-significant at $(0.05)$

for (CWL6) where (T) value was (4.626) with p-value (0.001), the mean of (Male) (11.336) and the mean of (Female) (10.7492).

- There was a highly significant difference at p-value (0.01) between (Male) and (Female) for (CWL6 at CEJ) where (T) value was (4.017) with p-value (0.001), the mean of (Male) (9.4874) and the mean of (Female) (8.95).

- There was a highly significant difference at p-value (0.01) between (Male) and (Female) for (CLL6) where (T) value was (10.946) with p-value (0.001), the mean of (Male) (5.273) and the mean of (Female) (4.511).

- There was non-significant difference at p-value (0.05) between (Male) and (Female) for (ETML6) where (T) value was (1.836) with p-value (0.07), the mean of (Male) (1.3388) and the mean of (Female) (1.3054).

- There was non-significant difference at $\mathrm{p}$ value (0.05) between (Male) and (Female) for 
(ETDL6) where (T) value was (1.832) with $\mathrm{p}$ value (0.07), the mean of (Male) (1.449) and the mean of (Female) (1.4002).

- There was non-significant difference at p-value (0.05) between (Male) and (Female) for (ETL6) where $(\mathrm{T})$ value was $(1.766)$ with p-value $(0.08)$, the mean of (Male) (1.775) and the mean of (Female) (1.7024).

\section{From table (3) we found the following:}

- There was a highly significant difference at p-value (0.01) between (Male) and (Female) for (ICW) where (T) value was (9.395) with p-value (0.001), the mean of (Male) (27.016) and the mean of (Female) (24.0176).

- There was a highly significant difference at p-value (0.01) between (Male) and (Female) for (IMW from fossa) where (T) value was (8.646) with p-value (0.001), the mean of (Male) (43.8952) and the mean of (Female) (39.904).

- There was a highly significant difference at p-value (0.01) between (Male) and (Female) for (Contact) where (T) value was (9.157) with p-value (0.001), the mean of (Male) (47.5536) and the mean of (Female) (43.8176).

- There was a non-significant difference at p-value (0.01) between (Male) and (Female) for (ADD) where $(\mathrm{T})$ value was $(0.743)$ with $\mathrm{p}$-value $(0.5)$, the mean of (Male) (32.7752) and the mean of (Female) (33.0376).

- There was a highly significant difference at p-value (0.01) between (Male) and (Female) for (ADM) where (T) value was (3.660) with p-value (0.001), the mean of (Male) (21.9976) and the mean of (Female) (23.084).

Table (4) shows that the discriminant coefficient was highest and positive of all parameters except (ETL3, ETML6 (enamel mesial), ETDL6 (enamel Distal ) \& ETL6 (AT CUSP TIP)) combined which indicates that these parameters and interaction of parameters are the determinants of differentiation between male and female, when evaluated singly were found to be significantly higher in males as compared to females $(\mathrm{p}<0.001)$.

TABLE (3): T- Test to illustrate the differences between the study sample according to Gender of Arch measurements

\begin{tabular}{lcccccc}
\hline & \multicolumn{2}{c}{ Variables } & \multicolumn{2}{c}{ Male $(\mathbf{n}=\mathbf{5 0})$} & \multicolumn{2}{c}{ Female $(\mathbf{n}=\mathbf{5 0})$} \\
& \multicolumn{2}{c}{ Mean \pm SD } & \multicolumn{2}{c}{ Mean \pm SD } & T & P-value \\
\hline ICW & 27.016 & 2.17 & 24.0176 & 0.63 & 9.395 & $0.001 \mathrm{HS}$ \\
IMW from fossa & 43.8952 & 3.01 & 39.904 & 1.27 & 8.646 & $0.001 \mathrm{HS}$ \\
Contact & 47.5536 & 2.82 & 43.8176 & 0.61 & 9.157 & $0.001 \mathrm{HS}$ \\
ADD & 32.7752 & 2.19 & 33.0376 & 1.19 & 0.743 & $0.5 \mathrm{NS}$ \\
ADM & 21.9976 & 1.84 & 23.084 & 1.01 & 3.660 & $0.001 \mathrm{HS}$ \\
\hline
\end{tabular}


TABLE (4): Factors discriminating between male and female subjects calculated using discriminant analysis.

\begin{tabular}{|c|c|c|c|c|c|}
\hline Parameter & Male & Female & $\begin{array}{l}\text { Difference } \\
\text { (d) }\end{array}$ & $\begin{array}{l}\text { Weight } \\
(\mathbf{x})\end{array}$ & $\begin{array}{c}d^{*} x \\
\text { (Discriminant coefficient) }\end{array}$ \\
\hline \multicolumn{6}{|l|}{ Lower canines (Right) } \\
\hline CWL3(width) & 7.017 & 6.308 & 0.709 & 0.361 & 0.256 \\
\hline CLL3 (length) & 9.916 & 9.361 & 0.555 & 0.890 & 0.494 \\
\hline ETL3 & 1.546 & 1.4192 & 0.127 & 0.963 & 0.122 \\
\hline \multicolumn{6}{|l|}{ Lower canines (Left) } \\
\hline CWL3 (width) & 6.978 & 6.296 & 0.683 & 0.503 & 0.344 \\
\hline CLL3 (length) & 10.197 & 9.284 & 0.914 & 0.692 & 0.632 \\
\hline ETL3 & 1.697 & 1.5904 & 0.662 & 0.967 & 0.640 \\
\hline \multicolumn{6}{|c|}{ Lower permanent $1^{\text {st }}$ molar (lower 6) (Right) } \\
\hline CWL6 (width) & 11.402 & 10.666 & 0.736 & 0.754 & 0.555 \\
\hline contact/at CEJ & 9.507 & 9.052 & 0.455 & 0.912 & 0.415 \\
\hline CLL6 (length) & 5.322 & 4.601 & 0.721 & 0.473 & 0.341 \\
\hline ETML6 (enamel mesial) & 1.269 & 1.2584 & 0.011 & 0.998 & 0.011 \\
\hline ETDL6 (enamel Distal) & 1.406 & 1.3508 & 0.055 & 0.966 & 0.053 \\
\hline ETL6 (AT CUSP TIP) & 1.788 & 1.7220 & 0.066 & 0.967 & 0.064 \\
\hline \multicolumn{6}{|c|}{ Lower permanent $1^{\text {st }}$ molar (lower 6) (Left) } \\
\hline CWL6 (width) & 11.336 & 10.749 & 0.587 & 0.821 & 0.482 \\
\hline contact/at CEJ & 9.487 & 8.950 & 0.537 & 0.859 & 0.461 \\
\hline CLL6 (length) & 5.273 & 4.511 & 0.762 & 0.450 & 0.343 \\
\hline ETML6 (enamel mesial) & 1.339 & 1.3054 & 0.034 & 0.967 & 0.033 \\
\hline ETDL6 (enamel Distal) & 1.449 & 1.4002 & 0.049 & 0.967 & 0.047 \\
\hline ETL6 (AT CUSP TIP) & 1.775 & 1.7024 & 0.073 & 0.969 & 0.071 \\
\hline \multicolumn{6}{|l|}{ Arch measurements } \\
\hline ICW & 27.016 & 24.018 & 2.998 & 0.526 & 1.577 \\
\hline IMW/ & 43.895 & 39.904 & 3.991 & 0.567 & 2.263 \\
\hline FROM CONTACT & 47.554 & 43.818 & 3.736 & 0.539 & 2.014 \\
\hline ADD & 32.775 & 33.038 & -0.262 & 0.994 & -0.260 \\
\hline \multirow[t]{2}{*}{$\mathrm{ADM}$} & 21.998 & 23.084 & -1.086 & 0.880 & -0.956 \\
\hline & & & & D square & 10.002 \\
\hline
\end{tabular}




\section{DISCUSSION}

Our measurements were driven from CBCT different cuts, as long as, linear measurements driven from CBCT images were proven to be accurate and reliable when compared to direct real measurements in many previous studies. ${ }^{[37-39]}$ Also there are no clinical differences between measurements using the CBCT method and those using the Digital Method (2D) digitalized plaster models. ${ }^{[40]}$

The use of different CBCT cuts, with adjusting the orientation line along the long axis of the selected teeth, allows us to measure the teeth length and enamel thickness easily that is not evaluated by this method to determine the sexual dimorphism before. In addition, the measurements of tooth size in terms of mesiodistal dimensions at two levels at contact point and at CEJ, for the same purpose, using $\mathrm{CBCT}$ image is unique.

In this study we analyzed 50 male and 50 female, the sample size was comparatively larger than the study conducted via CBCT on teeth sizes and arch measurements, ${ }^{[35]}$ and much higher than another study conducted via CBCT. ${ }^{[40]}$

In the present study, subjects with age between 18-25 years were selected because the growth and width of dental arch are completed and also, to exclude the effect of attrition of enamel occurring with age which may affect the enamel thickness or teeth sizes measurements. ${ }^{[6,41]}$

The results of this study concerning the mandibular canine teeth measurements including, crown mesiodistal (MD) width at contact level, crown width (MD) at CEJ level and crown length showed that, these measurements in male were larger than that of female with high significant differences. Elsehly et al., ${ }^{[30]}$ stated that sexual dimorphism was evident in MD dimension of mandibular canine among Egyptian with statistically significant differences favoring male over female, these results coincide with the current study. However, their measurements were done using multidetector computed tomography.
Our results on mandibular canine tooth measurements also were in accordance with Alam et al., ${ }^{[35]}$ who used 3D models gained from the CBCT to inspect tooth size and arch dimensions. They concluded that, the tooth size of canine showed the greater variation of the sexual dimorphism, larger in males and smaller in females. Same results attained by Shahid et al. ${ }^{[22]}$ but he used measurements obtained from digital caliper and digital stereomicroscope.

Our results on canine measurements (MD width) differ than that attained by Alam et al., 2019, ${ }^{[42]}$ who inspect the adult odontometrics by using 3D CBCT imaging in Various populations Saudi, Jordan and Egyptian population and they found that male showed larger measurements than female but without any significant differences. They finally, concluded that, the odontometric morphometry did not showed any variation in gender dimorphism. Other studies ${ }^{[43,44]}$ showed no significant differences between male and female measurements of mandibular canine, however their measurements were done by digital caliper on plaster model.

The results of this study concerning the mandibular first molar measurements including: the crown width (MD) at contact level, the crown width (MD) at CEJ level and the crown length of right and left side in male were larger than that of female with high significant differences.

Our results on either mandibular canines or mandibular first molar measurements showed similarities with many studies conducted on study cast. ${ }^{[6,13,45,46]}$ Or directly on oral cavity using digital caliper. ${ }^{[9]}$

Dalli et al., 2016 ${ }^{[6]}$ mentioned that, when different measurements of the tooth are compared, males have shown significant larger dimensions than that of females. this may be due to explanation introduced by Narang et al., 2015 ${ }^{[27]}$ that the Y chromosome raises the mitotic capacity of tooth germ and induces dentinogensis, while the $\mathrm{X}$ chromosome induces amelogensis resulting in the higher dentine and enamel thickness in male compared to females. 
About $90 \%$ of the genetic coding for amelobin (an organic component that makes up $90 \%$ of enamel) is found on $\mathrm{X}$ chromosome while the remaining $10 \%$ is located on Y-chromosomes in males. ${ }^{[47]}$ Some authors consider the change in the level of sex hormones during development may be related to the differences in proportions of dental tissues during teeth forming at different time. ${ }^{[27,48]}$ Therefore, disparities in enamel thickness between males and females could be supposed to be a parameter for sexual dimorphism.

In the current study we measured enamel thickness of mandibular $1^{\text {st }}$ molar on different areas, ETL6M, ETL6D and ETL6 at mesiolingual cusp tips at right and left sides and the enamel thickness at cusp tip of mandibular canine, we found that enamel thicknesses at all selected areas showed non- significant differences between males and females. These results is similar to study done by Harris and Hicks ${ }^{[4]}$ who stated that there is no distinct difference in enamel thickness between males and females after radiographic assessment of the enamel thickness in maxillary incisors. Stroud et al., ${ }^{[50]}$ found similar results regarding to enamel thickness of mandibular teeth using bitewing radiograph and they reported that the increased mesiodistal tooth size in male more than female is due to dentine thickness rather than enamel thickness. Moreover, Feeny et al., ${ }^{[51]}$ used measurements attained from microtomographic imaging and found similar results for mandibular canines' average enamel thickness.

On the contrary to our results, some researchers in studies using several methods, to determine the differences between males and females regarding enamel thickness, such as radiograph, model cast, animal teeth and ground section of extracted teeth, these studies reported that females showed significantly larger enamel thicknesses than males..$^{[25,47,48,52]}$

Our results regarding to mandibular arch measurements including ICW, IMW from fossa and IMW from contact points showed high significant differences between males and females with greater values in males more than females, which indicates the value of these measurements as a good determinant parameter of differentiation between males and females (table 4). Many studies agree with our results using several methods for arch measurements as digital caliper on cast ${ }^{[53]}$ or directly on oral cavity ${ }^{[9]}$, Stereomicroscope ${ }^{[22,54]}$ and 3D CBCT model $^{[35]}$.

Male's values of mandibular arch measurements exceeded female's values except for ADD where its values showed non-significant differences between males and females, while ADM showed reverse dimorphism as females' values were significantly larger than that of males. Reverse dimorphism has also been observed in other population in India by Acharya et al., ${ }^{[55]}$ and with Kirti et al.o, ${ }^{[46]}$ who found ICW in maxilla is higher in female which express reverse dimorphism in Kachari population, from which we could conclude that sexual dimorphism of teeth and arch measurements is population specific, the same conclusion reached by other author ${ }^{[27]}$

Males possess larger tooth crowns than females in contemporary human populations. This may be due to a longer period of amelogenesis for both deciduous and permanent dentition in males. ${ }^{[25]}$ The mesiodistal (MD) crown diameter of teeth is an important factor that affects the alignment of teeth in the bony arches and the development of occlusion during transition of dentition. ${ }^{[24,56]}$ moreover, arch dimensions could influence the diagnosis and treatment planning of orthodontist so digital methods to assess arch measurements should be considered as clinical assessment of orthodontic treatment. ${ }^{[57]}$

\section{CONCLUSION}

The study concluded that CBCT scanning allows us to measure the tooth size, enamel thickness and arch measurements, so CBCT will raise the issue of record keeping, tooth size and arch dimension measurements for analysis can be taken directly from the digital image. 
Moreover, the odontometric parameters including; mandibular canine, mandibular first molar crown width and length, inter-canine width and inter-molar width measurements based on CBCT imaging show highly significant gender difference. Thus, the parameters can be simple and reliable sexual dimorphism for medicolegal purpose and also it should be considered as part of the clinical diagnosis of orthodontic treatment and estimate of orthodontic clinical need in Egyptian population.

Further investigation on the effect of enamel thickness using CBCT images in sexual dimorphism is needed with wide age group and on late erupted teeth.

\section{REFERENCES}

1. Woelfel, J.B., R.C. Scheid, and G. Weiss, Woelfel's dental anatomy. 2012, Philadelphia: Wolters Kluwer : Lippincott Williams \& Wilkins.

2. Abou Neel E.A., Aljabo A., Strange A., Ibrahim s.,et al., Demineralization-remineralization dynamics in teeth and bone. Int J Nanomedicine, 2016. 11: p. 4743-4763.

3. Grewal D.S., Khangura R.K., Sircar K., Tyagi K.K., Kaur G., and David s. Morphometric Analysis of Odontometric Parameters for Gender Determination. J Clin Diagn Res, 2017. 11(8): p. Zc09-zc13.

4. Hosmani J.V., Nayak R.S., Kotrashetti V.S., s.p., and Babji D., Reliability of mandibular canines as indicators for sexual dichotomy. J Int Oral Health, 2013. 5(1): p. 1-7.

5. Vishwakarma, N. and R. Guha, A study of sexual dimorphism in permanent mandibular canines and its implications in forensic investigations. Nepal Med Coll J, 2011. 13(2): p. 96-9.

6. Dalli DT., Reddy S., Dathar S., Nallakunta R., Madugula P., and Darna G., Odontometrics: A Key to Gender Determination. World J Dent 2016. 7(3): p. 150-154.

7. Hasegawa I., Uenishi k., Fukunaga T., Kimura R., and Osawa M., Stature estimation formulae from radiographically determined limb bone length in a modern Japanese population. Leg Med (Tokyo), 2009. 11(6): p. 260-6.

8. Gupta S, Latoo SM, and D. MS., Mandibular canine index in gender determination: A viewpoint of a forensic odontologist. IAIM 2020. 7(8): p. 9-13.
9. Grover M., Bai RG., Ram T., Puri PM., and Ghodke KR., An odontologist's key to sex determination: Study analysis of mandibular canine teeth in south Indian population. . J Orofac Res., 2013.3(3): p. 157-60.

10. Hinchliffe, J., Forensic odontology, part 2. Major disasters. Br Dent J, 2011. 210(6): p. 269-74.

11. Sherfudhin, H., M.A. Abdullah, and N. Khan, A cross-sectional study of canine dimorphism in establishing sex identity: comparison of two statistical methods. J Oral Rehabil, 1996. 23(9): p. 627-31.

12. Urooge, A. and B.A. Patil, Sexual Dimorphism of Maxillary Sinus: A Morphometric Analysis using Cone Beam Computed Tomography. J Clin Diagn Res, 2017. 11(3): p. Zc67-zc70.

13. Khangura, R.K., K. Sircar, and D.S. Grewal, Four odontometric parameters as a forensic tool in stature estimation. $\mathrm{J}$ Forensic Dent Sci, 2015. 7(2): p. 132-6.

14. Iwamura, E.S., J.A. Soares-Vieira, and D.R. Muñoz, Human identification and analysis of DNA in bones. Rev Hosp Clin Fac Med Sao Paulo, 2004. 59(6): p. 383-8.

15. BilgeY., Kedici P.S., Alakoc Y.D. Ulkuer K.U., and Ilkyaz Y., The identification of a dismembered human body: a multidisciplinary approach. Forensic Sci Int, 2003. 137(23): p. 141-6.

16. Mohammed F., Fairozekhan A.T., Bhat S., and Menezes R.G., Forensic Odontology, in StatPearls. 2020, StatPearls Publishing LLC.: Treasure Island (FL).

17. Ayoub F., Shamseddine L., Rifai M., Cassia A., et al., Mandibular canine dimorphism in establishing sex identity in the lebanese population. Int J Dent, 2014. 2014: p. 235204.

18. Schwartz, G.T. and M.C. Dean, Sexual dimorphism in modern human permanent teeth. Am J Phys Anthropol, 2005. 128(2): p. 312-7.

19. Rawashdeh, M.A. and I.F. Bakir, The crown size and sexual dimorphism of permanent teeth in Jordanian cleft lip and palate patients. Cleft Palate Craniofac J, 2007. 44(2): p. 155-62.

20. Aiub, F., B. Subra, and K. Rifai, Detection of significant gender differences by odontometry as illustrated by a representative group from Lebanese (East-Mediterranean) population]. Sud Med Ekspert, 2005. 48(3): p. 22-3.

21. Adeyemi, T.A. and M.C. Isiekwe, Comparing permanent tooth sizes (mesio-distal) of males and females in a Nigerian population. West Afr J Med, 2003. 22(3): p. 219-21. 
22. Shahid F., Alam M.K., Khamis F., Honda Y.,et al., Geomorphometrics of Tooth Size and Arch Dimension Analysis by Conventional Digital Caliper and Digital Stereomicroscope to Establish Standard Norms for the Pakistani Population. Journal of Hard Tissue Biology, 2015. 24(2): p. 155-168.

23. Mohamed Abuelazayem, Sayed Hafez, and Foad Sharaby, Prevalence and Severity of Anterior Deep Bite in a Sample of Orthodontic Patients. Aust. J. Basic \& Appl. Sci., 2014. 8(15): p. 237-244.

24. Sravya T., Dumpala R.K., Guttikonda V.R. Manchikatla P.K., and Narasimha V.C., Mesiodistal odontometrics as a distinguishing trait: A comparative preliminary study. J Forensic Dent Sci, 2016. 8(2): p. 99-102.

25. Kapila R., Nagesh K.S. Lyengar A., and Mehkri S., Sexual dimorphism in human mandibular canines: a radiomorphometric study in South Indian population. J Dent Res Dent Clin Dent Prospects, 2011. 5(2): p. 51-4.

26. Rao N.G., Rao N.N., Pai M.L., and Kotian MS., Mandibular canine index--a clue for establishing sex identity. Forensic Sci Int, 1989. 42(3): p. 249-54.

27. Narang, R.S., A.S. Manchanda, and B. Singh, Sex assessment by molar odontometrics in North Indian population. J Forensic Dent Sci, 2015. 7(1): p. 54-8.

28. Aynechi N., Larson B.E., Leon-Salazar V., and Beiraghi S., Accuracy and precision of a 3D anthropometric facial analysis with and without landmark labeling before image acquisition. Angle Orthod, 2011. 81(2): p. 245-52.

29. Fourie, Z., et al., Evaluation of anthropometric accuracy and reliability using different three-dimensional scanning systems. Forensic Sci Int, 2011. 207(1-3): p. 127-34.

30. Elsehly WM., Hassn M., Emad M., Mohamed Z., Elshinety R., and Abd Elmeguid R., A Comparative Study on Some Odontometric Measurements among Adult Egyptian versus Adult Far Eastern Populations Using Multidetector Computed Tomography. JMSCR 2014. 2(2): p. 428-446.

31. Winter AA., Pollack AS., Frommer HH., and Koenig L., Cone beam volumetric tomography vs. medical CT scanners. N Y State Dent J, 2005. 71(4): p. 28-33.

32. Guerrero, M.E., Jacobs R., Loubele M., Schutyser F., Suetens P., and Van- Steenberghe D., State-of-the-art on cone beam CT imaging for preoperative planning of implant placement. Clin Oral Investig, 2006. 10(1): p. 1-7.
33. Ebrahim F., I.D., Kwon T., J. Sekoulidis, L. Caulley, and I. Zajaczkowski., Cone Beam CT For Preoperative Dental Implant Site Assessment: . An Evidence-Based Review of the Literature, 2009.

34. Saccucci M., Cipriani F., Carderi S., Di Carlo g., et al., Gender assessment through three-dimensional analysis of maxillary sinuses by means of cone beam computed tomography. Eur Rev Med Pharmacol Sci, 2015. 19(2): p. 185-93.

35. Alam M.K., Shahid F., Purmal K., Ahmed B., and Khamis M., Tooth size and Dental arch Dimension measurement through Cone beam Computed Tomography: Effect of Age and Gender. 2014.

36. Daubert D.M., Kelly J.L, Udod Y.G. Habor C., et al., Human enamel thickness and ENAM polymorphism. International Journal of Oral Science, 2016. 8(2): p. 93-97.

37. Alsamad,A.,Accuracy of Linear Measurements in Stitched Cone Beam Computed Tomographic Images An In-Vitro Stud. Egyptian Dental Journal, 2017. 63: p. 2435-2440.

38. Kopp, S. and P. Ottl, Dimensional stability in composite cone beam computed tomography. Dento maxillo facial radiology, 2010. 39(8): p. 512-516.

39. Tarazona-Álvarez, P., Romero-Millan J., Tarazona B., Fuster- Torres a., et al., Comparative study of mandibular linear measurements obtained by cone beam computed tomography and digital calipers. Journal of clinical and experimental dentistry, 2014. 6(3): p. e271-e274.

40. Tarazona, B., Liamas J.M., Cibrian R., Gandia J.L., and Paredes V., A comparison between dental measurements taken from CBCT models and those taken from a digital method. Eur J Orthod, 2013. 35(1): p. 1-6.

41. Brannon, R.B. and H.P. Kessler, Problems in mass-disaster dental identification: a retrospective review. J Forensic Sci, 1999. 44(1): p. 123-7.

42. Alam, M.K., Alzarea B.K., Ganji K.K., Kundi I., and Patil S., 3D CBCT human adult odontometrics: Comparative assessment in Saudi, Jordan and Egypt population. Saudi Dent J, 2019. 31(3): p. 336-342.

43. Al-Khateeb S.N. and E.S. Abu Alhaija, Tooth size discrepancies and arch parameters among different malocclusions in a Jordanian sample. Angle Orthod, 2006. 76(3): p. 459-65.

44. Asiry, M. and H. Hashim, Tooth size ratios in Saudi subjects with Class II, Division 1 malocclusion. 2012. 
45. Agrawal A., Manjunatha B.S. Dhiolia B., and Althmoli Y., Comparison of sexual dimorphism of permanent mandibular canine with mandibular first molar by odontometrics. J Forensic Dent Sci, 2015. 7(3): p. 238-43.

46. Kirti S., Rajeev K., and D. J., Sex determination based on Odontometric Analysis using Discriminant Function Analysis in Dimasa Kachari Population of Assam. J Forensic Sci \& Criminal Inves., 2019. 11(5): p. 555825.

47. Morgan, J., Metric sexual dimorphism in permanent canines. Bulletin of the International association for paleodontology, 2011. 5(1): p. 4-12.

48. Smith T.M., Olejniczak A.J., Reid D.J., Ferrell R.J., and Hupline j.j., Modern human molar enamel thickness and enamel-dentine junction shape. Arch Oral Biol, 2006. 51(11): p. 974-95.

49. Harris, E.F. and J.D. Hicks, A radiographic assessment of enamel thickness in human maxillary incisors. Arch Oral Biol, 1998. 43(10): p. 825-31.

50. Stroud, J.L., P.H. Buschang, and P.W. Goaz, Sexual dimorphism in mesiodistal dentin and enamel thickness. Dentomaxillofac Radiol, 1994. 23(3): p. 169-71.

51. Feeney R., Zermeno J., Reid D., Nakashima S., Sano H., et al., Enamel thickness in Asian human canines and premolars. Anthropological Science, v.118, 191-198 (2010), 2010. 118.
52. Monalisa W., Kokila G., Sharma H., Gopiathan P., Singh O., and Kumaraswamy S., Sexual dimorphism of enamel area, coronal dentin area, bicervical diameter and dentinoenamel junction scallop area in longitudinal ground section. Journal of oral and maxillofacial pathology : JOMFP, 2018. 22(3): p. 423-429.

53. Ling, J.Y. and R.W. Wong, Dental arch widths of Southern Chinese. Angle Orthod, 2009. 79(1): p. 54-63.

54. Al-Khatib AR., Rajiona ZA., Masudi SM., Anderson PJ., and Townsend GC., Tooth size and dental arch dimensions: a stereophotogrammetric study in Southeast Asian Malays. Orthodontics \& craniofacial research, 2011. 14(4): p.243-253.

55. Acharya A.B. and S. Mainali, Univariate sex dimorphism in the Nepalese dentition and the use of discriminant functions in gender assessment. Forensic Sci Int, 2007. 173(1): p. 47-56.

56. Yuen K.K., L.L. So, and E.L. Tang, Mesiodistal crown diameters of the primary and permanent teeth in southern Chinese-a longitudinal study. Eur J Orthod, 1997. 19(6): p. 721-31.

57. Islam R., Alam M.K., Shahid F., and Khamis M., Global Dental Arch Dimension Norms and Sexual Disparities: An overview. Bangladesh Journal of Medical Science, 2019. 18(1): p. 30-35. 